\title{
Article \\ Compensatory Ground Reaction Forces during Scoliotic Gait in Subjects with and without Right Adolescent Idiopathic Scoliosis
}

\author{
Paul S. Sung ${ }^{1, *(\mathbb{D})}$ and Moon Soo Park ${ }^{2}$ (D) \\ 1 Department of Physical Therapy, Indiana Wesleyan University, Marion, IN 46953, USA \\ 2 Department of Orthopaedic Surgery, Hallym University Dongtan Sacred Heart Hospital, \\ Medical College of Hallym University, Hwaseong-si 18450, Korea; abstract@hallym.ac.kr \\ * Correspondence: paul.sung@indwes.edu
}

Citation: Sung, P.S.; Park, M.S.

Compensatory Ground Reaction

Forces during Scoliotic Gait in

Subjects with and without Right

Adolescent Idiopathic Scoliosis.

Symmetry 2021, 13, 2372. https:/ /

doi.org/10.3390/sym13122372

Academic Editor: Jan Awrejcewicz

Received: 8 November 2021

Accepted: 1 December 2021

Published: 9 December 2021

Publisher's Note: MDPI stays neutral with regard to jurisdictional claims in published maps and institutional affiliations.

Copyright: (C) 2021 by the authors. Licensee MDPI, Basel, Switzerland. This article is an open access article distributed under the terms and conditions of the Creative Commons Attribution (CC BY) license (https:// creativecommons.org/licenses/by/ $4.0 /)$.

\begin{abstract}
Although the asymmetries of scoliotic gait in adolescent idiopathic scoliosis (AIS) groups have been extensively studied, recent studies indicated conflicting results regarding the ground reaction forces (GRFs) during gait in subjects with spinal deformity. The asymmetry during the stance phase might be clarified with three-dimensional (3D) compensations of GRFs between similar characteristics of subjects with and without AIS. The purpose of this study was to compare the normalized 3D GRF differences during the stance phase of gait while considering age, BMI, and Cobb angle between subjects with and without right AIS. There were 23 subjects with right convexity of thoracic idiopathic scoliosis and 22 age- and gender-matched control subjects. All subjects were right upper/lower limb dominant, and the outcome measures included the Cobb angles, normalized GRF, and KAI. The mediolateral (M/L) third peak force on the dominant limb decreased in the AIS group $(\mathrm{t}=2.58, p=0.01)$. Both groups demonstrated a significant interaction with the $3 \mathrm{D}$ indices $(\mathrm{F}=5.41$, $p=0.02$ ). The post-hoc analysis identified that the $\mathrm{M} / \mathrm{L}$ plane of asymmetry was significantly different between groups. The Cobb angles were negatively correlated with the vertical asymmetry index $(\mathrm{r}=-0.45, p=0.03)$; however, there was no significant correlation with age $(\mathrm{r}=-0.10, p=0.65)$ or body mass index $(r=-0.28, p=0.20)$. The AIS group demonstrated decreased GRF in the dominant limb M/L plane of the terminal stance phase. This compensatory motion was confirmed by a significant group difference on the M/L plane of the KAI. This KAI of vertical asymmetry correlated negatively with the Cobb angle. The asymmetric load transmission with compensatory vertical reactions was evident due to abnormal loading in the stance phase. These kinetic compensatory patterns need to be considered with asymmetry on the dominant limb when developing rehabilitation strategies for patients with AIS.
\end{abstract}

Keywords: idiopathic scoliosis; ground reaction forces; asymmetry index; kinetic; Cobb angle

\section{Introduction}

Ground reaction forces (GRFs) are clinically important measurements used to analyze asymmetric balance and altered postural sway in individuals with adolescent idiopathic scoliosis (AIS) during gait $[1,2]$. Although biomechanical factors contribute to the progression of scoliotic changes, individuals with AIS demonstrate altered postural alignment and compensatory reactions. The measurement of gait asymmetries and GRFs has been widely studied to analyze abnormal lower limb loading [2-4]. However, three-dimensional (3D) compensatory changes between subjects with and without AIS need to be carefully investigated to comprehensively evaluate joint loading during the stance phase of gait.

Since walking is considered a bipedal human activity, scoliotic changes might cause asymmetrical plantar pressure distribution, which leads to a disruption of dynamic balance. Several studies reported that the AIS group demonstrated balance deficits and increased fall risks compared to control subjects [5-7]. However, the vertical GRF is directly accompanied with gait asymmetry to mediolateral $(\mathrm{M} / \mathrm{L})$ and anteroposterior $(\mathrm{A} / \mathrm{P})$ planes 
when considering Cobb angle changes [8,9]. Several studies reported that AIS accompanies asymmetry between the left and right sides with a curved spine in the $\mathrm{M} / \mathrm{L}$ plane and inertial asymmetry with uneven $\mathrm{M} / \mathrm{L}$ distribution of the scoliotic changes $[1,10]$.

Kinematic asymmetry and rotational alignment of the thoracic spine of the scoliotic deformity have been reported [11,12]. These studies reported that the GRF asymmetry of the rotational moment and the angular momentum during gait were critical since the rotational moment results from the distribution of shear forces at the foot-to-ground interface. Other studies reported that the AIS group adjusted their Cobb angles, which are generally associated with greater asymmetry of GRF magnitudes in walking $[9,13]$. However, their studies did not carefully consider limb dominance or purposely excluded the frontal (M/L) plane of the GRF due to variations of the data in the AIS group $[8,9,14]$. Therefore, the results of these studies were limited since the convexities of the compensatory curves among the participants were varied and, more importantly, did not carefully consider homogeneous characteristics with the 3D GRF during gait.

Early onset scoliosis might be due to vertebral anomalies, neuromuscular dysfunctions, or scoliosis-associated idiopathic causes [15]. However, sagittal imbalance has been extensively described in the literature, whereas imbalance and malalignment in the frontal plane have not been carefully investigated [16]. A direction of convexity is correlated with handedness and the dominant eye $[17,18]$. Although limb dominance could not be directly related to kinetic asymmetry, there is a lack of study considering participants with similar dominant limbs to compare 3D changes.

It has been generally accepted that individuals with AIS possess rib humps in the thoracic region with contralateral shafts in the lumbar region [19-21]. A hypothetical mechanism has been used to explain the pathologic deformations within the vertebrae that result from the asymmetric load to an altered route of the load transmission on the convex side of the spine [22]. This asymmetric load condition alters the compensatory GRF for postural adaptation, and the asymmetrical pattern in individuals with AIS was integrated bilaterally in the frontal and transverse planes [2]. Consequently, the asymmetrical gait in AIS might be produced by changes in global postural control instead of changes in control of only one or two specific segments. The contradictory results of pelvic frontal motion were apparent, which was reduced without asymmetry on the GRF.

In our study, the kinetic asymmetry index (KAI) from the normalized GRF was compared while considering age and body mass index (BMI), which could contribute to the results of confounding variables in the study. Previously, a gait asymmetry index was utilized to compare the ratio from the difference between the left and right sides $[9,23]$. Other studies on AIS have examined combinations of factors, such as GRF, Cobb angle, age, and BMI [2,24,25]; however, no single study has examined the normalized 3D GRF compensations within similar characteristics between groups. Therefore, the purpose of this study was to compare the normalized 3D GRF differences during the stance phase of gait between groups while considering age, BMI, and Cobb angle. The hypothesis was that the AIS group would demonstrate a significantly different GRF asymmetry in the frontal plane. The secondary hypothesis was that the KAI would demonstrate a positive correlation with Cobb angle in the AIS group.

\section{Materials and Methods}

\subsection{Subjects}

Participants were recruited from a middle school $(n=372)$ health promotion program during approximately 10 months. The subjects were screened for scoliosis, which was confirmed by radiologic examination. As shown in Figure 1, a blinded examiner diagnosed the scoliosis based on a Cobb angle measurement. All participants had full-spine X-rays to measure their Cobb angles. As a result, 23 subjects with a Cobb angle greater than $10^{\circ}$ participated in the study. The purpose and study procedures were explained, and a signed consent form was obtained from the subjects' parents before data collection. 
The standardized experimental protocol was approved by the Institutional Review Board (0816A2 and 1225A3).

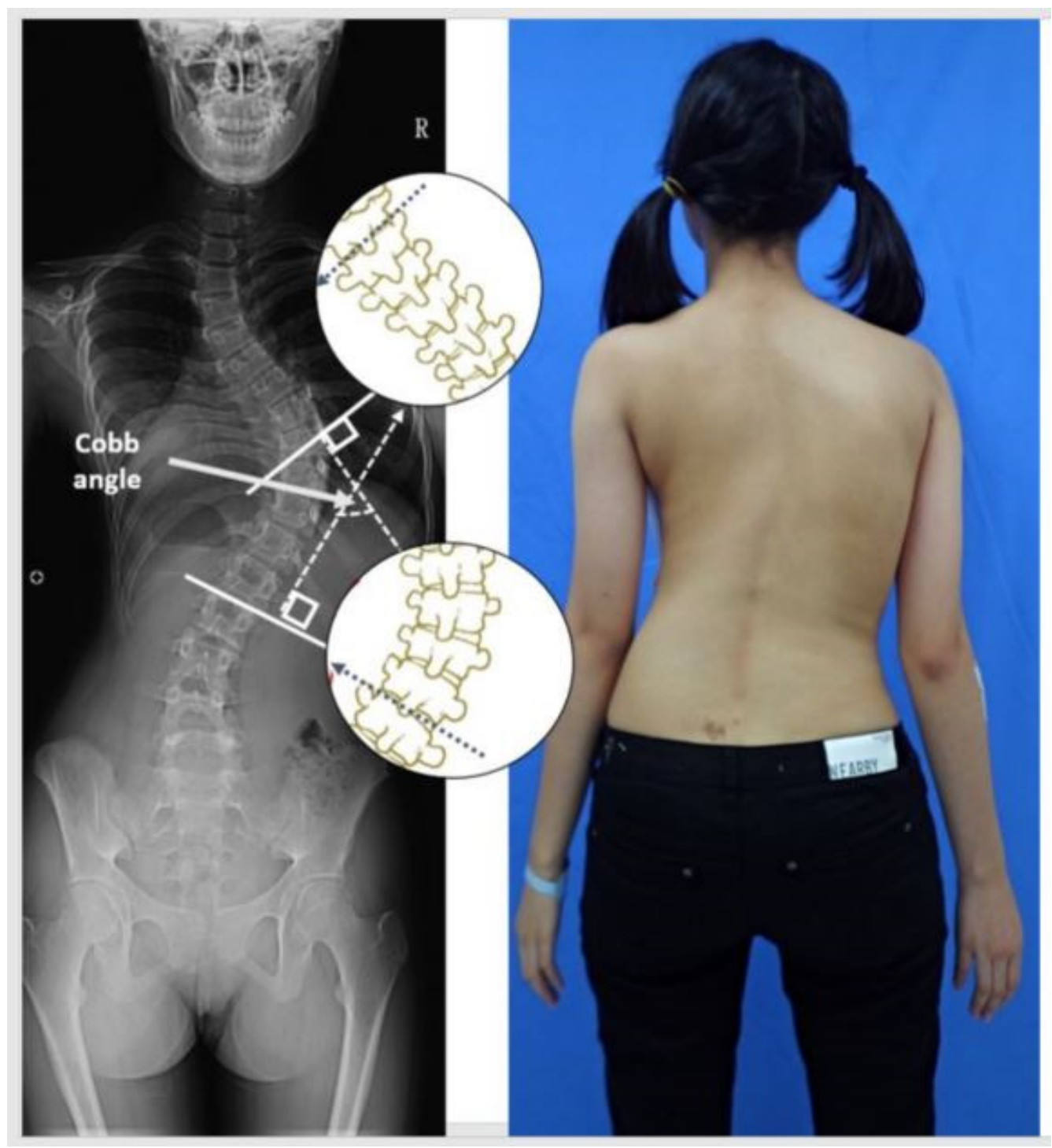

Figure 1. An example of the Cobb angle measurement. A blinded examiner carried out the measurements on the radiographs in random order. All X-rays were printed for manual measurement, and the most displaced cranial and caudal end vertebra of the curve were marked and calculated.

Signs of a motor grade, the sensory response of the upper and lower limbs, and pathological neurological responses were also evaluated. The AIS group was diagnosed with idiopathic scoliosis in the past one month and did not receive any treatment or undergo surgery prior to and during the study. In addition, all subjects were right limb dominant with a convexity on the right thoracic spine. All subjects were right-handed as determined by the Edinburgh Handedness questionnaire [26]. The subjects' right lower limbs were regarded as their dominant side since they preferred to use this limb to step out first when initiating gait $[23,27,28]$.

\subsection{Procedure}

The standardized procedures were explained to each subject prior to the experiment at the Motion Analysis Laboratory. Subjects were instructed to walk barefoot at a self-selected speed on a 10 m walkway, and a Motion Analysis System (Motion Analysis Corporation, 
Rohnert Park, CA, USA) was utilized for data collection. Two force platforms (AMTI OR6-7, Advanced Mechanical Technology, Inc., Watertown, MA, USA) were used to record the GRF (Fx, Fy, and Fz) in the orthogonal planes.

The modified Helen Hayes full trunk (with head) reflective marker set was attached to each subject with adhesive tape rings. A total of 34 reflective markers (12 mm diameter) were used to define and track a custom six-degree-of-freedom model [29,30]. Marker trajectories were low-pass filtered (6 Hz, 4th order Butterworth filter), and the time was synchronized within the test cycle into Matlab R2010b (The MathWorks Inc., Natick, MA, USA).

The force plates had to be hit at least five times with each foot during walking, but the subjects were not informed about the presence of the force plates. Subjects were unaware of the existence of the force platforms and were asked to walk as naturally as possible. The data were analyzed by customized software in MATLAB (The MathWorks, Inc., Natick, MA, USA). The average of the five stance phases of data were normalized for further analysis between the dominant and non-dominant limbs. The GRFs were analyzed in the three planes, and the data were checked for consistency. To calculate the selected gait parameters, such as stance and swing times, the A/P movement data of the heel marker was selected and filtered with a low-pass at $6 \mathrm{~Hz}$ using a fourth-order, zero lag, and Butterworth filter. The stance phase was normalized to a percent $(\%)$ in the gait cycle.

The GRF was collected in three axes ( $x$-axis: M/L force, $y$-axis: A/P force, $z$-axis: vertical force), which were selected and filtered with a low-pass at $15 \mathrm{~Hz}$ using a fourth-order, zero lag, and Butterworth filter at a sampling rate at $1200 \mathrm{~Hz}$. To capture kinematic data, reflective markers captured the motion three-dimensionally (Motion Analysis Corporation, Rohnert Park, CA, USA) with the sampling rate at $60 \mathrm{~Hz}$.

The GRF data were normalized to the body weight of each subject. The time was normalized to a percent of the stance phase. From the M/L plane ( $x$-axis), the negative peak (Fx1) and the two positive peaks (Fx2 and Fx3) were indicated (Figure 2). From the A/P plane ( $y$-axis), the positive peak (Fy1) and the negative peak (Fy2) were indicated. From the vertical plane (z-axis), three parameters (Fz1, Fz2, and Fz3) were indicated. The average of the peak values was used to analyze the data. For further analysis, the vertical component of the GRF was averaged from three peak forces.

In order to assess gait asymmetry, the KAI was calculated using the following formula $[8,31]: \mathrm{KAI}=|(\mathrm{XR}-\mathrm{XL}) /(0.5 \times(\mathrm{XR}+\mathrm{XL}))| \times 100$, where $\mathrm{XR}$ is a reaction force value of the dominant lower limb and $X \mathrm{~L}$ is a reaction force value of the non-dominant lower limb. The asymmetry level was calculated using KAI as the ratio from the difference between the limbs, which was normalized by the sum of both limb values. In this formula, a greater KAI implies a greater asymmetry between the limbs; therefore, the kinetic symmetry is higher when the KAI is closer to zero. Our study analyzed three specific planes separately based on $\mathrm{M} / \mathrm{L}, \mathrm{A} / \mathrm{P}$, and vertical KAI between groups to identify the KAI for each plane. 

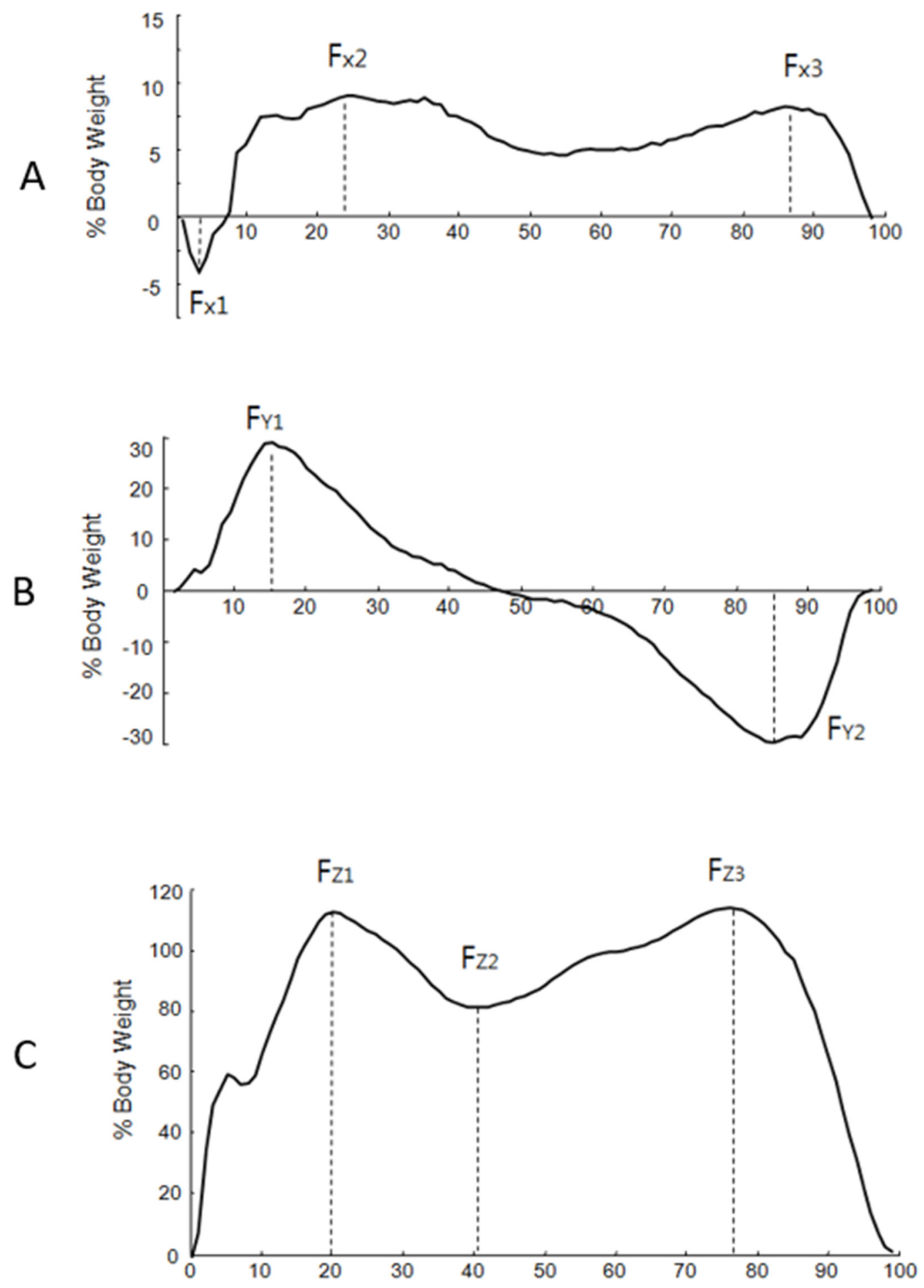

Figure 2. The typical pattern of the mediolateral $(\mathrm{M} / \mathrm{L})$, anteroposterior $(\mathrm{A} / \mathrm{P})$, and vertical planes of the ground reaction force. The horizontal line indicates the normalized stance phase, and the vertical line indicates the force percent body weight. (A) M/L plane: Fx1: first negative peak force, Fx2: second peak force, Fx3: third peak force. (B) A/P plane. Fy1: positive peak in anteroposterior, Fy2: negative peak. (C) Vertical plane: Fz1: vertical first peak force, Fz2: vertical second peak force, Fz3: vertical third peak force. 


\subsection{Statistical Analysis}

Statistical analyses were conducted using IBM Statistics 22 (IBM SPSS, Armonk, NY, USA). The dependent variables, including GRF, were normally distributed. The analysis using $G^{*}$ Power version 3.1.9.7 with expected power $=0.80, \alpha=0.05$, and effect size $f=0.5$ suggested that 22 participants per group would be necessary to yield a statistically significant difference [32].

The average amplitude of the GRF was compared by an independent $t$-test between groups. A mixed repeated measure analysis of variance (ANOVA) was utilized for the main effects on the KAI as well as the interactions between groups. The demographic factors, such as age and BMI, were used as covariates in order to eliminate confounding effects if a group difference was revealed. The post-hoc analysis was utilized for multiple comparisons to analyze group differences.

A Pearson correlation analysis was used to analyze the degree of associations between groups for the dependent variables. Pearson $r$ was interpreted as $0.0-0.25$ for little to no relationship, $0.26-0.50$ for a fair relationship, $0.51-0.75$ for a moderate relationship, and 0.76-1.00 for an excellent relationship [33]. For all statistical tests, the type I error rate was set at 0.05 .

\section{Results}

As shown in Table 1, there were 23 right thoracic AIS subjects ( 3 male, 20 female) and 22 age-matched control subjects ( 2 male, 20 female) who participated in the study (Chi-square $=0.18, p=0.52)$. There were no group differences on age $(\mathrm{t}=-0.57, p=0.56)$ or $\operatorname{BMI}(\mathrm{t}=0.56, p=0.57)$. The Cobb angle was measured in the AIS group, and the average was $23.14 \pm 4.50$ degrees on the right thoracic spine. The average walking speed was not significantly different $(t=-0.98, p=0.33)$ between groups (AIS subjects: $1.16 \pm 0.11 \mathrm{~m} / \mathrm{s}$ vs. control subjects: $1.12 \pm 0.16 \mathrm{~m} / \mathrm{s})$.

Table 1. The anthropometric characteristics between groups.

\begin{tabular}{lllll}
\hline & AIS Group (23) & Control Group (22) & Statistics & $p$ \\
\hline $\begin{array}{l}\text { Gender } \\
\text { (male/female) }\end{array}$ & $3 / 20$ & $2 / 20$ & Chi-square $=0.18$ & 0.52 \\
Age (years) & $14.96 \pm 1.02$ & $14.77 \pm 1.10$ & $\mathrm{t}=-0.57$ & 0.56 \\
BMI & $13.07 \pm 6.00$ & $14.21 \pm 7.49$ & $\mathrm{t}=0.56$ & 0.57 \\
Cobb angle (degrees) & $23.14 \pm 4.50$ & NA & NA & NA \\
\hline
\end{tabular}

Average \pm standard deviation, AIS: adolescent idiopathic scoliosis, BMI: body mass index, NA: not applicable.

The average amplitude of GRF and various parameters were compared between groups too (Table 2). As Figure 2 indicated, three planes of GRF were analyzed based on Fx1, Fx2, Fx3, Fy1, Fy2, Fz1, Fz2, and Fz3 for both limbs between groups. The AIS group demonstrated a significantly decreased Fx3 on the dominant limb compared with the control group $(7.40 \pm 3.44$ in the AIS group vs. $9.68 \pm 2.35$ in the control group; $t=2.58$, $p=0.01$ ).

Three planes of KAI were compared between groups by an independent $t$-test. The M/L plane increased significantly in the AIS group (11.55 \pm 2.59 in the AIS group vs. $5.08 \pm 1.19$ in the control group; $\mathrm{t}=2.23, p=0.03)$. However, the $\mathrm{A} / \mathrm{P}(1.58 \pm 0.59$ in the AIS group vs. $0.66 \pm 0.46$ in the control group; $t=-1.21, p=0.22)$ and vertical $(0.84 \pm 0.41$ in the AIS group vs. $0.52 \pm 0.15$ in the control group; $t=-0.64, p=0.52$ ) planes were not significantly different between groups (Figure 2). 
Table 2. The average amplitude of GRF between groups.

\begin{tabular}{clllll}
\hline & AIS Group & Control Group & $\begin{array}{l}\text { 95\% CI } \\
\text { Upper/Lower }\end{array}$ & t & $p$ \\
\hline Dominant limb & & & & & \\
Fx1 & $-8.85 \pm 3.91$ & $-7.75 \pm 4.61$ & $-1.46 / 3.67$ & 0.86 & 0.39 \\
Fx2 & $8.44 \pm 4.10$ & $10.12 \pm 2.94$ & $-0.47 / 3.83$ & 1.57 & 0.12 \\
Fx3 & $7.40 \pm 3.44$ & $9.68 \pm 2.35$ & $0.49 / 4.06$ & 2.58 & 0.01 * \\
Fy1 & $38.24 \pm 9.71$ & $40.65 \pm 6.81$ & $-2.65 / 7.48$ & 0.96 & 0.34 \\
Fy2 & $-45.56 \pm 9.90$ & $-44.99 \pm 7.42$ & $-4.74 / 5.87$ & 0.21 & 0.83 \\
Fz1 & $115.22 \pm 9.15$ & $119.28 \pm 8.36$ & $-1.22 / 9.33$ & 1.55 & 0.19 \\
Fz2 & $80.90 \pm 20.44$ & $83.98 \pm 6.72$ & $-6.16 / 12.31$ & 0.67 & 0.51 \\
Fz3 & $121.26 \pm 7.77$ & $121.22 \pm 6.55$ & $-4.36 / 4.30$ & -0.02 & 0.98 \\
Fx1 & $-4.93 \pm 2.72$ & $-4.63 \pm 2.84$ & $-1.37 / 1.97$ & 0.36 & 0.71 \\
Fx2 & $13.85 \pm 3.01$ & $14.43 \pm 3.19$ & $-1.28 / 2.43$ & 0.62 & 0.54 \\
Fx3 & $11.14 \pm 2.50$ & $11.87 \pm 2.46$ & $-0.77 / 2.22$ & 0.97 & 0.33 \\
Fy1 & $37.59 \pm 8.87$ & $40.27 \pm 8.71$ & $-2.61 / 7.97$ & 1.01 & 0.31 \\
Fy2 & $-42.44 \pm 7.63$ & $-43.90 \pm 7.75$ & $-6.09 / 3.16$ & -0.64 & 0.52 \\
Fz1 & $114.01 \pm 9.16$ & $115.55 \pm 9.11$ & $-3.95 / 7.03$ & 0.56 & 0.57 \\
Fz2 & $84.19 \pm 7.46$ & $85.42 \pm 6.46$ & $-2.98 / 5.43$ & 0.59 & 0.56 \\
Fz3 & $117.46 \pm 8.35$ & $118.68 \pm 5.27$ & $-3.01 / 5.44$ & 0.58 & 0.56 \\
\hline
\end{tabular}

Average \pm standard deviation, GRF: ground reaction force (\% body weight), AIS: adolescent idiopathic scoliosis, CI: confidence interval, Fx1: mediolateral negative first peak force, Fx2: mediolateral second peak force, Fx3: mediolateral third peak force, Fy1: positive peak in anteroposterior, Fy2: negative peak in anteroposterior, Fz1: vertical first peak force, Fz2: vertical second peak force, Fz3: vertical third peak force, ${ }^{*}: p<0.05$.

As shown in Figure 3, the mixed repeated ANOVA results indicated that the indices were significantly different $(\mathrm{F}=38.31, p=0.001)$, and the groups demonstrated an interaction on the three planes $(\mathrm{F}=5.41, p=0.02)$. The post-hoc analysis for the KAI confirmed that the $\mathrm{M} / \mathrm{L}$ plane (average 8.31) was significantly different compared to the A/P (average 9.43, $p=0.001$ ) and vertical (mean difference: $8.97, p=0.001$ ) planes.

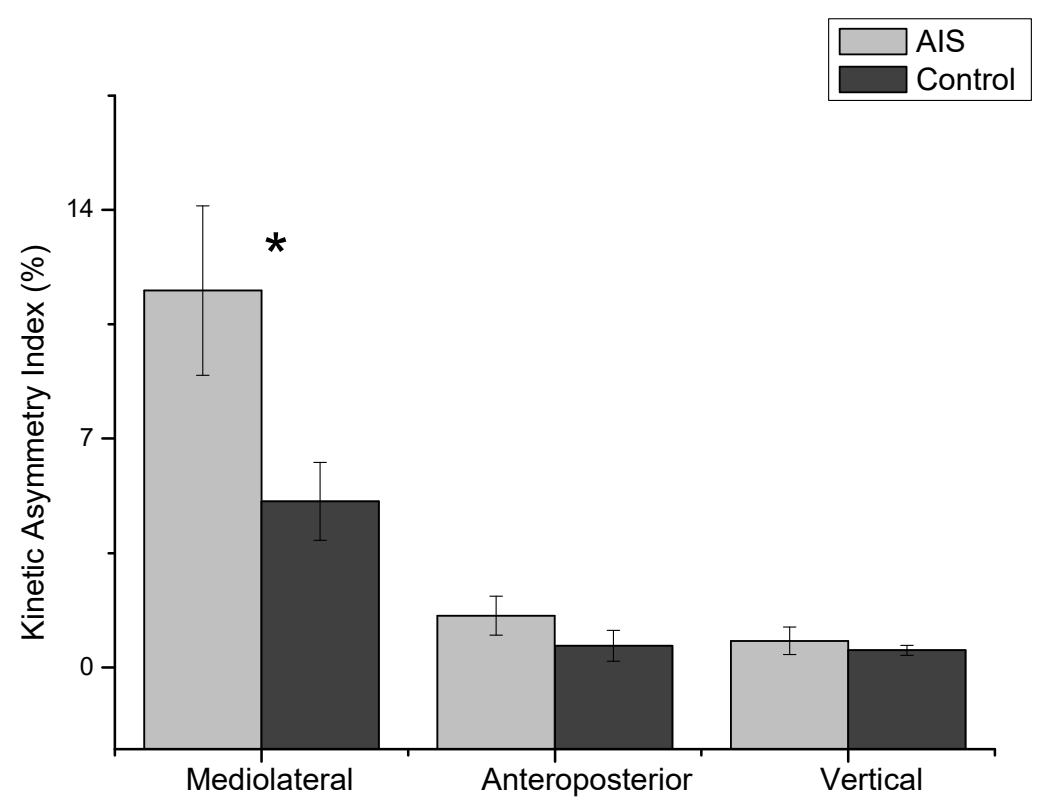

Figure 3. The absolute value of the kinetic asymmetry index (KAI) for three planes of the ground reaction force. The indices were significantly different $(\mathrm{F}=38.31, p=0.001)$, and the groups demonstrated a significant interaction $(\mathrm{F}=5.41, p=0.02)$. The mediolateral plane of the KAI was significantly greater in the AIS group than the control group $(\mathrm{t}=2.23, p=0.03){ }^{*}: p<0.05$. 
The correlation analyses were conducted to analyze the Cobb angle as well as the three planes of the KAI between groups (Table 3 ). The AIS group was significantly correlated with the Cobb angle and vertical plane of the KAI $(\mathrm{r}=-0.45, p=0.03)$. However, there was no significant correlation between groups based on the anthropometric variables.

Table 3. Correlation of the Cobb angle (degree) and KAI during walking.

\begin{tabular}{ccccccc}
\hline & & AIS Group & & \multicolumn{3}{c}{ Control Group } \\
\hline & Cobb Angle & Age & BMI & Cobb Angle & Age & BMI \\
\hline KAI_x & $-0.15(0.51)$ & $0.06(0.79)$ & 0.210 .33 & NA & 0.150 .49 & 0.400 .06 \\
\hline KAI_y & $-0.13(0.55)$ & $0.12(0.57)$ & $-0.02(0.94)$ & NA & $-0.02(0.93)$ & $-0.03(0.90)$ \\
\hline KAI_z & $-0.45(0.03) *$ & $0.02(0.92)$ & $-0.08(0.72)$ & NA & $-0.35(0.11)$ & $-0.04(0.83)$ \\
\hline
\end{tabular}

Correlation coefficient (significant $p$ value), KAI: normalized kinetic asymmetry index (no unit), AIS: adolescent idiopathic scoliosis, $\mathrm{x}$ : mediolateral, $\mathrm{y}$ : anteroposterior, z: vertical, BMI: body mass index, NA: not applicable, ${ }^{*}: p<0.05$.

\section{Discussion}

The results of our study indicated that the GRF showed a statistically significant difference between groups in the frontal plane of the dominant limb. While gait patterns are cyclical, it is important to accommodate balance to adequately compensate gait function. Our first hypothesis was that the AIS group would demonstrate significantly different GRF asymmetry in the frontal plane in the stance phase. We accepted this hypothesis as there was compensation in the M/L plane during walking in the AIS group. Another study partially supported our findings that a right thoracic curve leads to extra weight on the right limb, which is needed to initiate stepping [34].

The average walking speeds of the AIS subjects $(1.16 \pm 0.11 \mathrm{~m} / \mathrm{s})$ and control subjects $(1.12 \pm 0.16 \mathrm{~m} / \mathrm{s})$ were similar to previously reported walking speeds for this age group $[9,11]$. A right thoracic curve leads to a shift in the center of mass (COM); consequently, stepping initiation with the right limb was more difficult than the left limb for the AIS group. The functional consequences were compensated for as increased right thorax convexity of the upper body COM from the midsagittal plane may have resulted in increased limb laterality based on the GRF magnitudes. This gait asymmetry was related to adaptations from the dominant limb [23]. The control group was able to integrate dominant limb dependency to enhance gait performance. This adaptive strategy was reflected by the asymmetric load conditions, which altered compensatory patterns for balance and postural control [19-21].

The results of our study indicated that the KAI demonstrated a significant interaction with groups since the M/L plane of the KAI significantly increased in the AIS group. A greater KAI indicated increased kinetic asymmetry between the limbs in the AIS group compared to the control group. This gait asymmetry was from the thoracic spine convexity and the altered route of the load transmission, as the observed gait asymmetry was due to "global postural control" rather than "isolated segments" with dissociated trunk motion [2,24].

While AIS is a deformation of the spine, previous results indicated that constrained differential growth in the sagittal plane can result in lateral bending and rotation without a pre-existing left-right asymmetry [35]. These pathologic deformations within the vertebrae in scoliosis resulted from the convex side of the curve. Results of our study supported that the gait asymmetry and Cobb angles might be related to functional consequences of the right thorax convexity.

A plantar pressure asymmetry was also reflected by the increased amplitude of Fx3 (the third mediolateral peak) on the dominant limb in order to compensate for the symmetrically rotating pelvis and lower limbs. Our results indicated that the AIS group demonstrated a significantly decreased $\mathrm{Fx} 3$ on the dominant limb compared with the control group. The group difference in this stance phase was critical to maintain balance during single limb standing. Our subjects were all right limb dominant; however, there was no group difference on the non-dominant limb during the stance phase. 
The secondary hypothesis was that the KAI would demonstrate a positive correlation with Cobb angle in the AIS group. Greater Cobb angles were expected to be positively associated with greater asymmetry indices. However, greater Cobb angles (i.e., more severe scoliosis) are associated with lower vertical KAI. The kinetic asymmetry might be associated with an increased right thorax convexity when considering age and BMI. This compensatory vertical KAI indicated the reactions from greater Cobb angles in the AIS group. The negative correlation in vertical asymmetry might explain the potential compensatory $\mathrm{M} / \mathrm{L}$ asymmetry on the dominant limb with the third mediolateral peak (Fx3).

A possible mechanism related to altered postural control in the terminal stance phase may be the consequence of compensatory strategies to avoid pain or injury [36,37]. Subjects with scoliosis were less capable of adapting their upper and lower limbs to the optimal coordination pattern during trunk rotations [18]. It is generally accepted that gait patterns are cyclical, and we observed that Fx1 gradually increased during the stance phase and decreased at Fx3. In addition, our results indicated that a compensatory vertical KAI indicated a negative relationship from greater Cobb angles in the AIS group. Although an asymmetrical pattern of vertical GRF was observed [9,38], single limb support in midstance involves progression of the body over the foot and weight-bearing stability in the $\mathrm{M} / \mathrm{L}$ plane [39].

It could be argued that spatiotemporal parameters significantly differ across different age groups [40]. Their results were based on healthy adults as the aging factor showed more cautious gait; however, the age range of our subjects was 13 to 16 years old. Likewise, we did not have any significant correlations between BMI and KAI as the average range of the BMI in both groups was 13.07 to 14.96. Other studies reported that BMI can impact postoperative outcomes and that obesity may be related to a larger curve in the AIS group [41,42].

In our previous report, the spinal muscle responses were related to hand dominance as part of the explanatory model and assumed that dominant- and nondominant-handed subjects are not unique cohorts [43]. This postural adaptation was secondary to the scoliotic changes for the generated hypothesis in the mechanism of production of scoliosis [2,22]. Other studies supported our results since they performed side-to-side gait symmetry and showed that scoliosis patients demonstrated a symmetrical pattern of the GRF in the vertical and $\mathrm{A} / \mathrm{P}$ planes [8,12]. The Cobb angle may contribute more to $\mathrm{M} / \mathrm{L}$ gait asymmetry, and previous GRF data also found that the AIS group had asymmetrical gait compared to the control group [2].

The AIS group generally demonstrated a mirrored $S$ shape on their spinal deformity. The right convexity of the thoracic spine curve may affect pelvis alignment in the posterior view [13], such as the lower pelvis, thereby lowering the left lower limb. This could produce more flexion on the non-dominant limb through the knee or hip in order to maintain an efficient energy cost by keeping the up-down movement of the COM in a smaller range [44]. Another study reported that the postures were correlated with somatic development, composition, and body structure. Proper body composition and somatic structure might be gradually changed away from the unilateral [45]. Their results partially supported our results that smaller vertical peak forces were evident on the dominant limb in the stance phase. Our results of normalized GRF might reflect a consistency of coordinated trunk motion, which was significantly lower in the AIS group in the transverse and frontal planes [4]. Their results indicated that thorax-pelvis coordination demonstrated less gait stability in the AIS group.

There were several limitations to this study. First, the individual characteristics within the groups might make it limited to generalize the results of this study. However, the anthropometric variables were used as covariates to eliminate confounding effects for the data analyses. Further studies warrant proactive recruitment of a substantially larger sample size with full distribution of age and BMI to detect those variables. Second, our study was a cross-sectional design, which may not explain a cause-and-effect relationship. 
However, enhanced trunk rotation might be coordinated for limited thorax motion by adaptation through motor learning in the AIS group.

\section{Conclusions}

The ground reactions were compared between AIS subjects and age- and gender-matched control subjects during the stance phase of gait. The asymmetric load transmission with compensatory vertical reactions was evident due to abnormal loading in the stance phase. The compensatory kinetic asymmetry needs to be considered when developing rehabilitation strategies for altered routes of the load transmission in adolescents with scoliosis.

Author Contributions: Conceptualization, P.S.S. and M.S.P.; methodology, P.S.S.; validation, M.S.P. and P.S.S.; formal analysis, M.S.P. and P.S.S.; investigation, P.S.S.; resources, M.S.P. and P.S.S.; data curation, P.S.S.; writing—original draft preparation, M.S.P. and P.S.S.; writing—review and editing, M.S.P. and P.S.S.; visualization, P.S.S.; supervision, P.S.S.; project administration, P.S.S. All authors have read and agreed to the published version of the manuscript.

Funding: This work was supported by the Basic Science Research Program through the National Research Foundation of Korea funded by the Ministry of Education, Science and Technology (20100003015).

Institutional Review Board Statement: The study was conducted according to the guidelines of the Declaration of Helsinki and approved by the Institutional Review Board of Korea University (protocol numbers: 0816A2; date of approval 22 January 2012 and 1225A3; date of approval 12 June 2012).

Informed Consent Statement: Written informed consent has been obtained from the patients to publish this paper.

Data Availability Statement: The data presented in this study are available on request from the corresponding author.

Conflicts of Interest: None of the authors has any financial or personal conflict of interest in relation to the submission, other people, or any organizations.

\section{References}

1. Nault, M.L.; Allard, P.; Hinse, S.; Le Blanc, R.; Caron, O.; Labelle, H.; Sadeghi, H. Relations between standing stability and body posture parameters in adolescent idiopathic scoliosis. Spine 2002, 27, 1911-1917. [CrossRef]

2. Yang, J.H.; Suh, S.W.; Sung, P.S.; Park, W.H. Asymmetrical gait in adolescents with idiopathic scoliosis. Eur. Spine J. 2013, 22, 2407-2413. [CrossRef]

3. Yang, F.; Kim, J.; Munoz, J. Adaptive gait responses to awareness of an impending slip during treadmill walking. Gait Posture 2016, 50, 175-179. [CrossRef] [PubMed]

4. Park, H.J.; Sim, T.; Suh, S.W.; Yang, J.H.; Koo, H.; Mun, J.H. Analysis of coordination between thoracic and pelvic kinematic movements during gait in adolescents with idiopathic scoliosis. Eur. Spine J. 2016, 25, 385-393. [CrossRef]

5. Sahin, F.; Urak, O.; Akkaya, N. Evaluation of balance in young adults with idiopathic scoliosis. Turk. J. Phys. Med. Rehabil. 2019, 65, 236-243. [CrossRef] [PubMed]

6. Anari, J.B.; Tatad, A.; Cahill, P.J.; Flynn, J.M.; Harms Study, G. The Impact of Posterior Spinal Fusion (PSF) on Coronal Balance in Adolescent Idiopathic Scoliosis (AIS): A New Classification and Trends in the Postoperative Period. J. Pediatr. Orthop. 2020, 40, e788-e793. [CrossRef] [PubMed]

7. Ozkunt, O.; Karademir, G.; Sariyilmaz, K.; Gemalmaz, H.C.; Dikici, F.; Domanic, U. Analysing the change of sagittal balance in patients with Lenke 5 idiopathic scoliosis. Acta Orthop. Traumatol. Turc. 2017, 51, 377-380. [CrossRef]

8. Yusof, M.I.; Shaharudin, S.; Sivalingarajah, P. Does Vertical Ground Reaction Force of the Hip, Knee, and Ankle Joints Change in Patients with Adolescent Idiopathic Scoliosis after Spinal Fusion? Asian Spine J. 2018, 12, 349-355. [CrossRef] [PubMed]

9. Chockalingam, N.; Dangerfield, P.H.; Rahmatalla, A.; Ahmed, E.N.; Cochrane, T. Assessment of ground reaction force during scoliotic gait. Eur. Spine J. 2004, 13, 750-754. [CrossRef] [PubMed]

10. Park, Y.S.; Lim, Y.T.; Koh, K.; Kim, J.M.; Kwon, H.J.; Yang, J.S.; Shim, J.K. Association of spinal deformity and pelvic tilt with gait asymmetry in adolescent idiopathic scoliosis patients: Investigation of ground reaction force. Clin. Biomech. 2016, 36, 52-57. [CrossRef] [PubMed]

11. Allard, P.; Chavet, P.; Barbier, F.; Gatto, L.; Labelle, H.; Sadeghi, H. Effect of body morphology on standing balance in adolescent idiopathic scoliosis. Am. J. Phys. Med. Rehabil. 2004, 83, 689-697. [CrossRef] [PubMed]

12. Kramers-de Quervain, I.A.; Muller, R.; Stacoff, A.; Grob, D.; Stussi, E. Gait analysis in patients with idiopathic scoliosis. Eur. Spine J. 2004, 13, 449-456. [CrossRef] [PubMed] 
13. Schizas, C.G.; Kramers-de Quervain, I.A.; Stussi, E.; Grob, D. Gait asymmetries in patients with idiopathic scoliosis using vertical forces measurement only. Eur. Spine J. 1998, 7, 95-98. [CrossRef] [PubMed]

14. Syczewska, M.; Graff, K.; Kalinowska, M.; Szczerbik, E.; Domaniecki, J. Influence of the structural deformity of the spine on the gait pathology in scoliotic patients. Gait Posture 2012, 35, 209-213. [CrossRef] [PubMed]

15. Guo, J.; Liu, Z.; Lv, F.; Zhu, Z.; Qian, B.; Zhang, X.; Lin, X.; Sun, X.; Qiu, Y. Pelvic tilt and trunk inclination: New predictive factors in curve progression during the Milwaukee bracing for adolescent idiopathic scoliosis. Eur. Spine J. 2012, 21, $2050-2058$. [CrossRef]

16. Cunin, V. Early-onset scoliosis: Current treatment. Orthop. Traumatol. Surg. Res. 2015, 101, S109-S118. [CrossRef]

17. Obeid, I.; Berjano, P.; Lamartina, C.; Chopin, D.; Boissiere, L.; Bourghli, A. Classification of coronal imbalance in adult scoliosis and spine deformity: A treatment-oriented guideline. Eur. Spine J. 2019, 28, 94-113. [CrossRef]

18. Sahlstrand, T. An analysis of lateral predominance in adolescent idiopathic scoliosis with special reference to convexity of the curve. Spine 1980, 5, 512-518. [CrossRef] [PubMed]

19. Sung, P.S.; Park, M.S. Lumbar spine coordination during axial trunk rotation in adolescents with and without right thoracic idiopathic scoliosis. Hum. Mov. Sci. 2020, 73, 102680. [CrossRef] [PubMed]

20. Bruyneel, A.V.; Chavet, P.; Bollini, G.; Allard, P.; Mesure, S. The influence of adolescent idiopathic scoliosis on the dynamic adaptive behaviour. Neurosci. Lett. 2008, 447, 158-163. [CrossRef]

21. Schlosser, T.P.; van Stralen, M.; Brink, R.C.; Chu, W.C.; Lam, T.P.; Vincken, K.L.; Castelein, R.M.; Cheng, J.C. Three-dimensional characterization of torsion and asymmetry of the intervertebral discs versus vertebral bodies in adolescent idiopathic scoliosis. Spine 2014, 39, E1159-E1166. [CrossRef]

22. Kotwicki, T.; Walczak, A.; Szulc, A. Trunk rotation and hip joint range of rotation in adolescent girls with idiopathic scoliosis: Does the "dinner plate" turn asymmetrically? Scoliosis 2008, 3, 1. [CrossRef]

23. Pal, G.P. Mechanism of production of scoliosis. A hypothesis. Spine 1991, 16, 288-292. [CrossRef] [PubMed]

24. Sadeghi, H.; Allard, P.; Prince, F.; Labelle, H. Symmetry and limb dominance in able-bodied gait: A review. Gait Posture 2000, 12, 34-45. [CrossRef]

25. Schlager, B.; Krump, F.; Boettinger, J.; Niemeyer, F.; Ruf, M.; Kleiner, S.; Beer, M.; Wilke, H.J. Characteristic morphological patterns within adolescent idiopathic scoliosis may be explained by mechanical loading. Eur. Spine J. 2018, 586, 5622. [CrossRef]

26. Schlosser, T.P.; van der Heijden, G.J.; Versteeg, A.L.; Castelein, R.M. How 'idiopathic' is adolescent idiopathic scoliosis? A systematic review on associated abnormalities. PLoS ONE 2014, 9, e97461. [CrossRef]

27. Oldfield, R.C. The assessment and analysis of handedness: The Edinburgh inventory. Neuropsychologia 1971, 9, 97-113. [CrossRef]

28. Brophy, R.; Silvers, H.J.; Gonzales, T.; Mandelbaum, B.R. Gender influences: The role of leg dominance in ACL injury among soccer players. Br. J. Sports Med. 2010, 44, 694-697. [CrossRef]

29. Andersen, T.E.; Floerenes, T.W.; Arnason, A.; Bahr, R. Video analysis of the mechanisms for ankle injuries in football. Am. J. Sports Med. 2004, 32, 69-79. [CrossRef] [PubMed]

30. Sung, P.S. Increased double limb support times during walking in right limb dominant healthy older adults with low bone density. Gait Posture 2018, 63, 145-149. [CrossRef]

31. Buczek, F.L.; Rainbow, M.J.; Cooney, K.M.; Walker, M.R.; Sanders, J.O. Implications of using hierarchical and six degree-of-freedom models for normal gait analyses. Gait Posture 2010, 31, 57-63. [CrossRef] [PubMed]

32. Herzog, W.; Nigg, B.M.; Read, L.J.; Olsson, E. Asymmetries in ground reaction force patterns in normal human gait. Med. Sci. Sports Exerc. 1989, 21, 110-114. [CrossRef] [PubMed]

33. Faul, F.; Erdfelder, E.; Lang, A.G.; Buchner, A. G*Power 3: A flexible statistical power analysis program for the social, behavioral, and biomedical sciences. Behav. Res. Methods 2007, 39, 175-191. [CrossRef]

34. Portney, L.G.; Watkins, M.P. Foundations of Clinical Research Applications to Practice, 3rd ed.; Pearson Education Inc.: Upper Saddle River, NJ, USA, 2009.

35. Bruyneel, A.V.; Chavet, P.; Bollini, G.; Allard, P.; Berton, E.; Mesure, S. Dynamical asymmetries in idiopathic scoliosis during forward and lateral initiation step. Eur. Spine J. 2009, 18, 188-195. [CrossRef]

36. Crijns, T.J.; Stadhouder, A.; Smit, T.H. Restrained Differential Growth: The Initiating Event of Adolescent Idiopathic Scoliosis? Spine 2017, 42, E726-E732. [CrossRef]

37. Lee, D.; Sung, P.S. Comparison of kinematic similarity index during gait between adults with and without nonspecific chronic neck pain. Gait Posture 2021, 91, 99-104. [CrossRef] [PubMed]

38. Sung, P.S.; Schalk, B.M.; Latuszek, N.; Hosmer, E. Compensatory spinopelvic motions with and without a handheld task following a perturbation in standing between subjects with and without chronic low back pain. Gait Posture 2020, 76, 7-13. [CrossRef]

39. Perry, J. Gait Analysis: Normal and Pathological Function; SLACK Inc.: Thorofare, NJ, USA, 1992.

40. Herssens, N.; Verbecque, E.; Hallemans, A.; Vereeck, L.; Van Rompaey, V.; Saeys, W. Do spatiotemporal parameters and gait variability differ across the lifespan of healthy adults? A systematic review. Gait Posture 2018, 64, 181-190. [CrossRef]

41. Gilbert, S.R.; Savage, A.J.; Whitesell, R.; Conklin, M.J.; Fineberg, N.S. BMI and magnitude of scoliosis at presentation to a specialty clinic. Pediatrics 2015, 135, e1417-e1424. [CrossRef]

42. Tarrant, R.C.; Queally, J.M.; Moore, D.P.; Kiely, P.J. Prevalence and impact of low body mass index on outcomes in patients with adolescent idiopathic scoliosis: A systematic review. Eur. J. Clin. Nutr. 2018, 72, 1463-1484. [CrossRef] 
43. Sung, P.S.; Spratt, K.F.; Wilder, D.G. A possible methodological flaw in comparing dominant and nondominant sided lumbar spine muscle responses without simultaneously considering hand dominance. Spine 2004, 29, 1914-1922. [CrossRef] [PubMed]

44. Mahaudens, P.; Detrembleur, C.; Mousny, M.; Banse, X. Gait in adolescent idiopathic scoliosis: Energy cost analysis. Eur. Spine J. 2009, 18, 1160-1168. [CrossRef] [PubMed]

45. Wilczynski, J.; Bieniek, K. Correlations of somatic traits and postural defects in girls and boys aged 10-12. Acta Bioeng. Biomech. 2019, 21, 79-86. [PubMed] 